\title{
CHEMICAL CONTROL OF RHEOTAXIS IN ASELLUS
}

\author{
W. C. ALLEE
}

Marine Biological Laboratory and Lake Forest College ${ }^{1}$

TEN FIGURES

CONTENTS

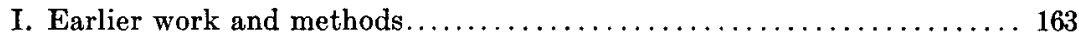

II. Electrolytes......................................... 165

1. Chlorine salts of alkali metals ......................... 165

2. Different anions with cation potassium $\ldots \ldots \ldots \ldots \ldots \ldots \ldots \ldots, 171$

3. Chlorine salts of alkali earths....................... 173

4. Antagonisms .................................... 175

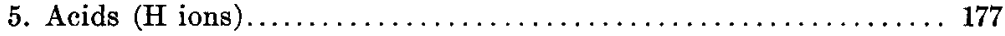

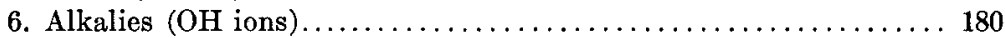

7. Distilled water.................................... 181

III. Non-electrolytes........................................ 183

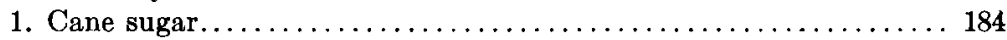

IV. Metabolism and rheotaxis............................ 186

1. Does resistance to sodium cyanide measure the metabolic rate of

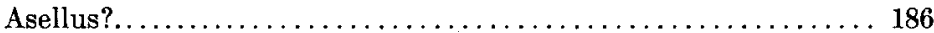

2. Effect of potassium chloride.............................. 188

2. Effect of calcium chloride.............................. 189

4. Effect of cane sugar............................... 193

V. Summary ......................................... 195

VI. Literature cited .................................. 197

\section{EARLIER WORK AND METHODS}

Certain conditions known to affect the metabolism of animals are known regularly to affect the rheotactic reactions of the isopod Asellus communis Say. Lowered oxygen tension, chloretone, potassium cyanide, lowered temperature, suddenly increased temperature, increased carbon dioxide tension, and

1 The experiments upon which this paper is based were carried on at Woods Hole during the summers of 1913 , ' 14 , and '15. During this time 1003 individual isopods were tested in a total of 13,245 minute reaction periods. I am indebted directly and indirectly to many people with whom I have talked during the progress of the work, particularly to Dr. F. B. Coffin, for aid with certain phases of the chemistry of the problem. 
starvation, all of which depress the rate of animal metabolism, also decrease the positive rheotactic response of these isopods. Heightened oxygen tension, caffein, and a gradual increase in temperature have the opposite effect ('12, '13). ${ }^{2}$

Changes in the percentage of the positive rheotactic reaction are correlated with resistance to potassium cyanide ('14) and with changes in carbon dioxide production (Allee and Tashiro '14). At the present time their resistance to cyanide and their carbon dioxide production furnish the best known indices of the rate at which metabolism is carried on in these small organisms.

Essentially the same method of testing the rheotactic tendency has been used throughout this series of isopod experiments. The animals to be tested, usually three in number, are placed in a waxbottomed enamel ware pan $25 \mathrm{~cm}$. in diameter and 6 $\mathrm{cm}$. deep in $2 \mathrm{~cm}$. of water to which they are accustomed. The pan is placed in diffuse light and after standing for about fifteen minutes a current is set up by stirring with the bulb end of an ordinary pipette. Rheotactic reactions given in a circular current have been found comparable with those given in a straight current and because of the greater speed with which tests may be made the circular current method has been exclusively used in these experiments. Great care is taken to create an approximately uniform rate of current. The reaction of each isopod is taken for one minute and these are separately recorded. As a rule this is repeated ten times but with highly toxic chemicals the preliminary interval was shortened and only five trials were made.

The chemicals used were Kahlbaum's c. f. a. in all cases except caesium chloride which was Baker's 'Standard Purity.' The solutions were made with distilled water using the molecular weights in Chemiker Kalender for 1913. Allowance was made for water of crystallization but no quantitative tests were run even in the deliquescent salts. However, the experiments on calcium chloride and magnesium chloride were repeated each

${ }^{2}$ Numerals standing alone refer to my earlier papers. 
of the three summers that the work was in progress with similar results so that weight variations must have been slight.

The isopods used in these experiments were all Asellus communis Say, collected from the 'dump pond' in Woods Hole. The animals used were mainly immature and were rarely in the laboratory more than three days before experimentation began. When first collected they gave the low rate of positive reactions that is usual for Asellus from such ponds. They were kept in the laboratory under low or high oxygen conditions according to the demands of the experiments for animals with low or high rates of positive rheotaxis.

\section{ELECTROLYTES}

\section{Chlorine salts of the alkali metals}

All the chemicals tested in the concentrations used will cause a decrease in the positive rheotactic reaction if allowed to act for sufficient time; and at one stage the investigation virtually became a search for reagents that would cause an increase in the positiveness of the reaction. Of the cations tested only rubidium and potassium showed a strong consistent increase. Sodium and barium have similar but less pronounced effects.

The results of the trials with the chlorine salts of the alkaline metals in $\mathrm{N} / 10$ solutions (except sodium chloride which is $\mathrm{N} / 5$ ) are given in figure 1. The cations are arranged in order of their atomic weights which are shown by the solid line with short cross marks. Each space in the ordinates equals 5 units of the atomic weight. As the atomic weight of these metals increases the ionic velocity and electronegativeness decreases. The simple broken line gives the percentage that at some time in the treatment showed some increase in the positiveness of their rheotactic reaction. The dotdash line shows the difference in the percentage of positive rheotaxis before treatment and at the most positive period during treatment. In both these lines each space in the ordinates has a value of 5 per cent.

The unbroken line in the figure represents the relative toxicity of the different salts which is reckoned by the average time in 


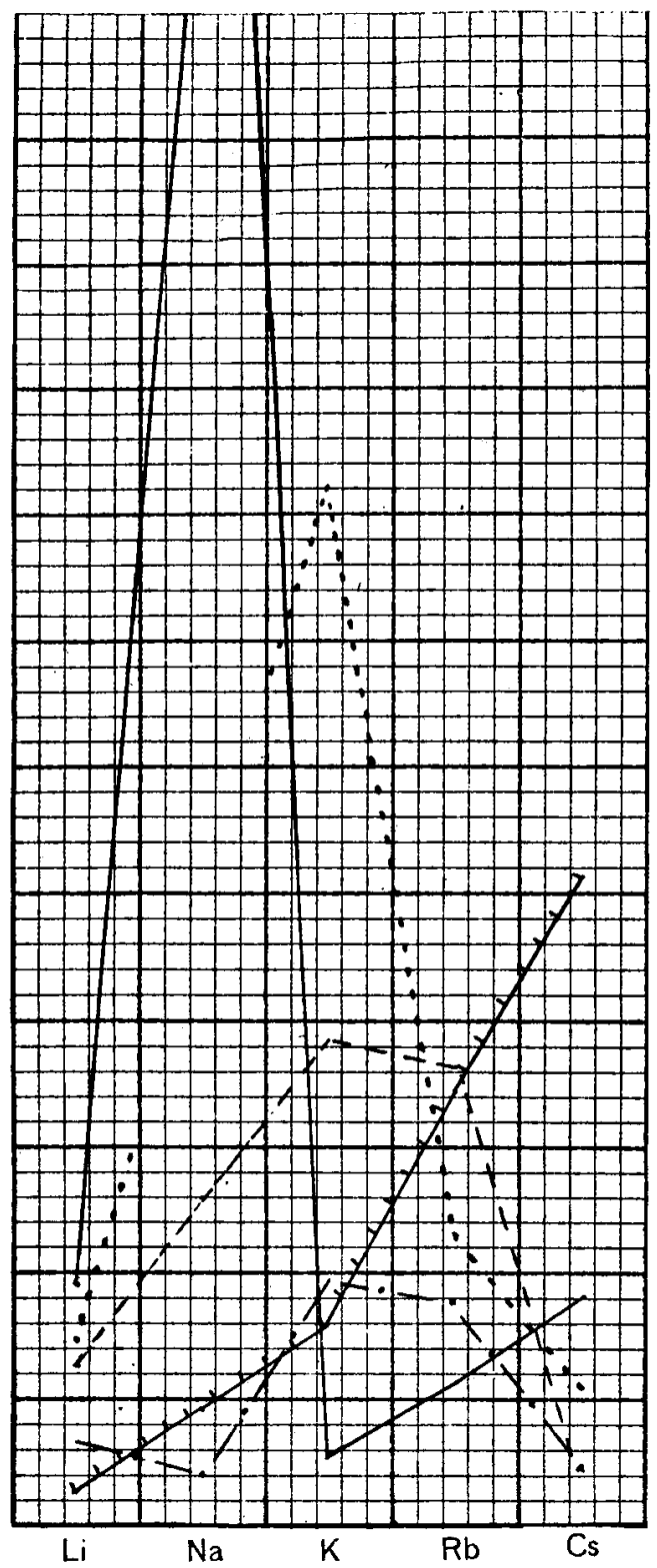

Fig. 1 Showing relative toxicity and relative effect of chlorine salts of the alkali metals on positive rheotaxis of Asellus. For methods of charting see text p. 165. 
minutes elapsing before the isopods lost the power to stand. This turning time may or may not be correlated with the survival time of the individual but since it shows the time during which the animal may react it is more important in the study of certain phases of behavior than the death time of the animal. In this curve each space in the ordinates represents twelve minutes. The dotted line gives the ratio existing between the beginning of depression and the turning time reduced to percentage of the latter. This ratio will be called the toxicity. depression ratio and is shown here with each ordinate space worth 2 per cent.

The distribution of the experiments on which these curves are based is shown in table 1 .

\section{TABLE 1}

Showing the number of rheotactic experiments performed with the different strengths of the chlorine salts of the alkali metals

\begin{tabular}{|c|c|c|c|c|}
\hline CATION & $\mathrm{N} / 5$ & $N / 10$ & $\mathrm{~N} / 20$ & $N / 40$ \\
\hline $\begin{array}{l}\mathrm{Li} \ldots \ldots \ldots \\
\mathrm{Na} \ldots \ldots \ldots \\
\mathrm{K} \ldots \ldots \ldots \ldots \\
\mathrm{Rb} \ldots \ldots \ldots \\
\mathrm{Cs} \ldots \ldots \ldots\end{array}$ & $\begin{array}{r}17 \\
78 \\
2\end{array}$ & $\begin{array}{l}74 \\
89 \\
21\end{array}$ & 7 & 27 \\
\hline
\end{tabular}

If one considers the percentage of isopods having their rheotactic reaction made more positive the order of effectiveness is $\mathrm{Li}<\mathrm{Na}<\mathrm{K}>\mathrm{Rb}>\mathrm{Cs}$. When the amount of increase in positiveness is compared $\mathrm{N} / 5$ sodium chloride is less effective than $\mathrm{N} / 10$ lithium chloride but if $\mathrm{N} / 5$ solutions of both salts are compared the former is more effective and the above order holds for the amount of increase as well as for the number made more positive. If this series be written in the ordinary physiological style it is $\mathrm{Cs}<\mathrm{Li}<\mathrm{Na}<\mathrm{Rb}<\mathrm{K}$ with a sharp division between the sodium and rubidium. This reminds one of the usual physiological order of these cations except that caesium which usually lies between lithium and sodium in its effects on living tissues and colloids (Höber '14, s. 487) here is less effective than either. 
The chlorides of potassium and rubidium were found to be most efficient in increasing the positiveness of the rheotactic reaction. These salts are chemically closely related and must represent the optimum of the series of conditions that are found in the alkali metal series. The effect of these two cations (with the chlorine anion) is so striking that it is worth while exhibiting the result of their action. The effect of rubidium chloride may be seen in table 2 and that of potassium chloride in table 5, p. 190 .

TABLE 2

Showing some diagrammatic reversals in the sign of the rheotactic reaction caused by $\mathrm{N} / 10 \mathrm{RbCl}$

\begin{tabular}{|c|c|c|c|c|c|c|c|c|c|c|c|}
\hline \multirow[t]{2}{*}{$\begin{array}{c}\text { Isopod } \\
\text { No. }\end{array}$} & \multicolumn{4}{|c|}{ RHEOTAXIS BEFORE TREATMENT } & \multicolumn{4}{|c|}{ RHEOTAXIS AFTER TREATMENT } & \multirow{2}{*}{$\frac{\begin{array}{c}\text { TIME } \\
\text { TRE'T'D }\end{array}}{\text { min. }}$} & \multirow[t]{2}{*}{$\mid \begin{array}{c}\text { SIZE } \\
\text { IN MM. }\end{array}$} & \multirow[t]{2}{*}{ TEMP. } \\
\hline & + & - & $\alpha$ & $\mathrm{E}^{1}$ & + & - & $\alpha$ & $\mathrm{E}^{1}$ & & & \\
\hline 514 & & 100 & & 2.25 & 100 & & & 1.0 & 16 & 7.5 & 25 \\
\hline 525 & 30 & & 70 & 0.90 & 80 & 20 & & 1.0 & 10 & 6.0 & 21 \\
\hline 526 & & 100 & & 2.65 & 60 & 20 & 20 & 1.7 & 16 & 7.0 & 21 \\
\hline 527 & & 100 & & 3.25 & 80 & 20 & & 0.5 & 16 & 8.0 & 21 \\
\hline 528 & & 90 & 10 & 1.65 & 60 & 20 & 20 & 0.8 & 8 & 6.0 & 23 \\
\hline 529 & & 100 & & 3.00 & 100 & & & 1.7 & 17 & 6.0 & 23 \\
\hline 531 & 10 & 90 & & 2.55 & 100 & & & 1.8 & 26 & 6.0 & 23 \\
\hline 532 & 20 & 20 & 60 & 1.00 & 100 & & & 1.4 & 15 & 7.0 & 23 \\
\hline 533 & 10 & & 90 & 1.10 & 80 & & 20 & 1.2 & 15 & 7.0 & 23 \\
\hline Ave.. & 8 & 67 & 25 & 2.04 & 84 & 9 & 7 & 1.2 & 15 & 6.7 & \\
\hline
\end{tabular}

1 The figures in these columns give in a standardized from the amount of movement of the isopods during their rheotactic test. For detailed account see '13, p. 261.

The cases listed in the rubidium table are selected and are the most diagrammatic obtained with that reagent while those shown for potassium include all the tests for a given experiment which explains the apparently greater efficiency of rubidium.

The stimulating effect of potassium and rubidium chlorides was noticeable in the general behavior and particularly in the increased rapidity of movement of the isopods. One of many similar laboratory notes for rubidium (N/10 solution) is : "Isopod became nervously active immediately although it had been sluggish before." Another for potassium (N/10) is "All nervous, excited, although losing power of coördination." Continued 
exposure even to these stimulating salts results in a decrease in the positiveness of the reaction but at times, particularly in potassium chloride, this decrease comes only when the isopods lose coördination through the toxic action of the solution. They may either lose power of positive orientation while still strongly stimulated or may orient repeatedly but be unable to hold the position. While in this state the isopods have a tendency to run in small circles of about a centimeter in diameter. Similar circular reactions have been observed under natural conditions but not to the extent produced in these solutions. Sodium chloride, the next most stimulating salt, gives none of these phenomena and its stimulating action is slower as well as less pronounced.

It has been shown that a relationship exists between the positiveness and the efficiency (the distance covered during a minute reaction period) of the rheotactic reaction ('13). This has since been amply confirmed in the study of reactions under natural conditions or under such depression as may be caused by calcium chloride or cane sugar. That the two phases of the reaction are not correlated at all times is shown by the experiments with rubidium and potassium chlorides just mentioned and is typically illustrated by the results shown in table 2 . In the trials listed there the positiveness of the isopods was increased markedly in all cases but in all save one the efficiency of the response decreased, and while the positive rheotactic reaction was increased 76 per cent the efficiency was cut almost in half. In the very beginning of the treatment the activity increased as has been noted but the subsequent depression often came before the isopods lost the power of positive orientation.

This toxicity-depression ratio (dotted line figure 1) which was high in the case of potassium and relatively so with rubidium was quite low with lithium and caesium both of which depress the rheotactic positiveness long before the toxic effect is apparent.. The ratio was not found for sodium because the toxicity was not accurately determined.

In considering the relative toxicity of the different alkali metal cations it should again be noted that the comparison in the figure (unbroken line) is between $\mathrm{N} / 5$ sodium as compared 
with $\mathrm{N} / 10$ solutions of the other cations. Even with this difference sodium is least toxic, followed after a long interval by lithium, caesium, rubidium and potassium in the order named. The favorable effect of sodium chloride is shown by the fact that ten isopods were reacting after eleven hours and at fourteen hours six of these were more positive than at the beginning. Three were still reacting after sixteen hours and lived for five days in $\mathrm{N} / 5$ solution.

The cation $\mathrm{NH}_{4}$ is chemically closely related to the other members of this group and is often similar in physiological action to potassium which it particularly resembles. In its effect on rheotaxis, however, ammonium chloride is less effective than caesium chloride so that the complete series would be $\mathrm{NH}_{4}<$ $\mathrm{Cs}<\mathrm{Li}<\mathrm{Na}<\mathrm{Rb}<\mathrm{K}$. The toxicity effect of ammonium is like that of potassium and rubidium as shown by the series $\mathrm{Na}<\mathrm{Li}<\mathrm{Cs}<\mathrm{Rb}<\mathrm{NH}_{4}<\mathrm{K}$. This is in the same order as has been found to preserve the irritability of fresh frog's nerve (Brodsky '08, vide Höber s. 511); to cause recovery of irritability after loss in cane sugar solution (Höber, s. 497) namely: $\mathrm{Na}<\mathrm{Li}<\mathrm{Cs}<\mathrm{NH}_{4}<\mathrm{Rb}<\mathrm{K}$. The only difference is that in the foregoing instance ammonium stands next to rubidium while with the isopods it is next to potassium.

I am unable to state why ammonium should act in its usual manner as regards toxicity and not as regards rheotaxis. The rheotactic reaction may be influenced by the well developed nervous system of the isopods or by direct action on the muscles or by a combination of the two. It may be we have here a differential effect in that potassium stimulates the muscles more than it depresses the central nervous system while ammonium acts in the opposite manner. Mathews ('07) found that these two cations have similar effect on muscles and on motor nerves but are opposed in their effect on the central nervous system, which potassium depresses while ammonium stimulates it to the point of tetanic convulsions. The action may also be explained by assuming that ammonium produces a greater permeability than potassium such as Lillie ('09) discovered with Arenicola larvae. It is known (Mathews '07) that the am- 
monium salts may be eccentric in their action and Mathews interprets this as due largely to their hydrolytic dissociation but this explanation is unsatisfactory so far as the present work is concerned because of the slight amount of this kind of dissociation in the solution strengths used.

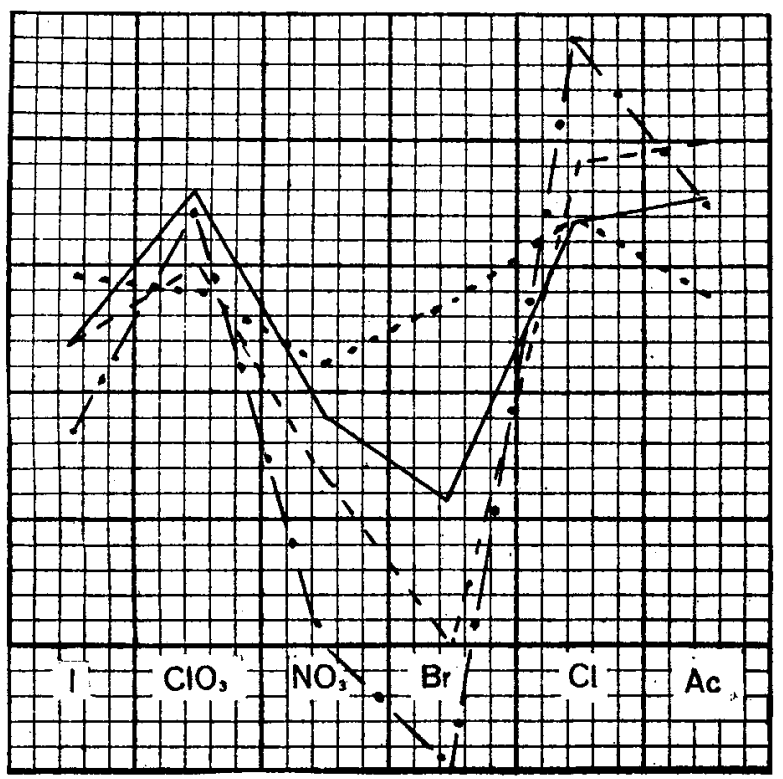

Fig. 2 Showing relative toxicity and the relative effect of different anions with the cation potassium on positive rheotaxis of Asellus. For details see text p. 172 .

\section{Different anions with the cation potassium}

Some work was carried on to find whether different anions with the most effective cation, potassium, also affected rheotaxis. The studies were only carried far enough to demonstrate that the anions are effective and to suggest in a tentative way the order of their relative effect. The findings with $\mathrm{N} / 10$ solutions, which was the strength most often used, are shown in figure 2.

Figure 2 is charted in much the same manner as the preceding figure. The anions are arranged in their usual relative colloidal 
and physiological effect (Höber, s. 308). Again the simple broken line shows the percentage of isopods that were made more positive at some time during the treatment with each ordinate space worth 5 per cent. The dot-dash line gives the average difference between the percentage of positive rheotaxis before and at the most positive point after treatment with each ordinate space equal to 2 per cent. The unbroken line gives toxicity, each ordinate space representing one minute, and the dotted line shows the toxicity-depression ratio with the ordinate spaces worth 5 per cent.

Experiments with potassium sulphocyanide in $\mathrm{N} / 5$ solution showed that it was more toxic than any other anion tried at this strength. In $N / 20$ solution it caused some increase in positive rheotaxis but the evidence of the experiments at hand is contradictory and there are too few instances to locate this anion definitely. Potassium sulphate $(2 \mathrm{~N} / 7$ and $\mathrm{N} / 15)$ increased the positiveness of the response, especially in the weak strength where it was almost as effective as potassium chloride in $\mathrm{N} / 10$ solution but more toxic.

As the figure shows the relative toxicity was $\mathrm{Br}>\mathrm{NO}_{3}>\mathrm{I}>$ $\mathrm{Cl}>A c, \mathrm{ClO}_{3}$, and the effect on positive rheotaxis was $\mathrm{Br}<$ $\mathrm{NO}_{3}<\mathrm{I}<\mathrm{ClO}_{3}<\mathrm{Cl}<A c$ if one considers the effectiveness in causing some increase in the positiveness. The same order holds true when the extent of the increase is considered except that $A c$ is less effective than $\mathrm{ClO}_{3}$ and Cl. I am not prepared to state why the order found here differs from the usual relative effect shown by the order of arrangement in the figure or why the more toxic salts should vary in their toxicity and their effect on rheotaxis. It is possible that more experiments might change the order in one or two places, but enough tests have been made to demonstrate conclusively that potassium chloride is the most effective salt so far as amount of change is concerned, and the regularity with which bromine takes the usual place of iodine at this concentration indicates that the order found is not a mere accident. A number of the anions that failed to show a marked increase in $\mathrm{N} / 10$ solution were tested in $\mathrm{N} / 20$ and $\mathrm{N} / 40$ concentration. No marked change occurred except in 
the bromide-iodide relation just mentioned. At the weakest concentration the bromide became more effective than either the nitrate or the iodide and took its usual place in the anion series viz: $\mathrm{NO}_{3}<\mathrm{I}<\mathrm{Br}<A c$.

It is noteworthy that the toxicity-depression ratio is uniformly high which means that the potassium cation, regardless of the anion, tends to cause the isopods to give a positive reaction well after the amount of activity is markedly depressed. The variation in effect of these anions on rheotaxis must be due in part to some other factor than relative toxicity because the toxicitydepression ratio does not vary sufficiently to account for the rheotactic results obtained.

\section{Chlorine salts of the alkali earths}

Although any chemical at the concentrations used will ultimately cause a decrease in rheotactic positiveness, calcium and strontium chlorides were found to be particularly effective in causing this depression without preliminary stimulation. Barium and magnesium chlorides also cause an ultimate depression but they often give a preliminary period of stimulation.

Some of the experimental data on which these conclusions are based are shown in table 3 which shows the toxicity of $M / 5$

TABLE 3

Showing the toxicity and effect on rheotaxis of chlorine salts of alkali earths. Strontium chloride experiments were run in $\mathrm{N} / 5$ and the others in $\mathrm{M} / 5$ solutions. Isopods with an initial response of more than 71 per cent positive were not considered

\begin{tabular}{|c|c|c|c|c|c|c|}
\hline \multicolumn{4}{|c|}{ TOXICITY } & \multicolumn{3}{|c|}{ RHEOTAXIS } \\
\hline $\begin{array}{l}\text { Cation } \\
\text { (1) }\end{array}$ & $\underset{\text { (2) }}{\text { Number }}$ & $\underset{\text { (3) }}{\text { Toxicity time }}$ & $\frac{\text { Depression }}{\begin{array}{c}\text { toxicity } \\
(4)\end{array}}$ & $\underset{(5)}{\text { Number }}$ & $\begin{array}{l}\text { Per cent } \\
\text { more posi- } \\
\text { tive } \\
\text { (b) }\end{array}$ & $\begin{array}{c}\text { Amount of } \\
\text { increase } \\
\text { (7) }\end{array}$ \\
\hline $\mathrm{Mg}$. & 10 & 8 hrs. $^{1}$ & 21 & 32 & 31 & -9 \\
\hline $\mathrm{Ca} .$. & 6 & 3 hrs. $^{1}$ & 6 & 21 & 0 & -36 \\
\hline Sr. . & 11 & $58 \mathrm{~min}$. & 26 & 7 & 14 & -11 \\
\hline $\mathrm{Ba} \ldots \ldots \ldots$ & 12 & $\left\{\begin{array}{l}1 \mathrm{hr} . \\
30 \mathrm{~min} .\end{array}\right.$ & 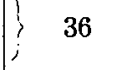 & 10 & 50 & +18 \\
\hline
\end{tabular}

${ }^{1}$ Active after. 
solutions of barium, calcium and magnesium chlorides and of $\mathrm{N} / 5$ solution of strontium chloride, together with their effect on positive rheotaxis. The different columns have the following significance: No. 2 shows the number of isopods on which the toxicity time was determined; No. 3 gives the average toxicity; No. 4 gives the ratio of toxicity-depression in percentages of the toxicity time; No. 5 lists the number of rheotactic tests made whose results are shown in the next two columns; No. 6 shows the percentage of isopods that showed some increase in rheotactic positiveness during the treatment and the last column gives the amount of the increase or decrease at the most positive period of treatment.

Strontium chloride is decidedly more toxic than any of the others; barium comes next and after an interval comes calcium with magnesium much the least toxic. Calcium chloride at M 5 concentration failed to give a preliminary increase in the positive rheotaxis but it did cause an increase in 5 per cent of all the trials made at all concentrations. Calcium also caused a marked decrease in positiveness even when the most positive responses are considered. The low percentage shown by the ratio of depression to toxicity indicates that unlike potassium and rubidium the depression is not due primarily to toxicity.

Strontium chloride acts much as calcium chloride except that it is less effective in the concentration used and more toxic. Although magnesium stimulated approximately one-third of the isopods during the first 45 minutes of treatment the average effect of the treatment was a decrease in positiveness.

Barium chloride caused a greater initial stimulation than any other chloride tried excepting only those of potassium and rhubidium and possibly sodium. In percentage of individual stimulated, in amount of stimulation, and in the relatively high toxicity-depression ratio barium aligns itself with the alkali metal group. This is in keeping with its usual physiological action which has been known since Ringer ('86) found that it acted with the alkali metals rather than as the other alkali earths. 


\section{Antagonisms}

When isopods are treated alternately with potassium and calcium chlorides the well known antagonistic action of the two salts is plainly shown. The effect of such treatment on eight isopods is graphically exhibited in figures 3,4 , and 5. In making these trials the isopods were tested as usual in water to which they were accustomed, then dried momentarily on filter paper and introduced into the desired solution. After about a minute they were given five one minute trials and again placed in water.

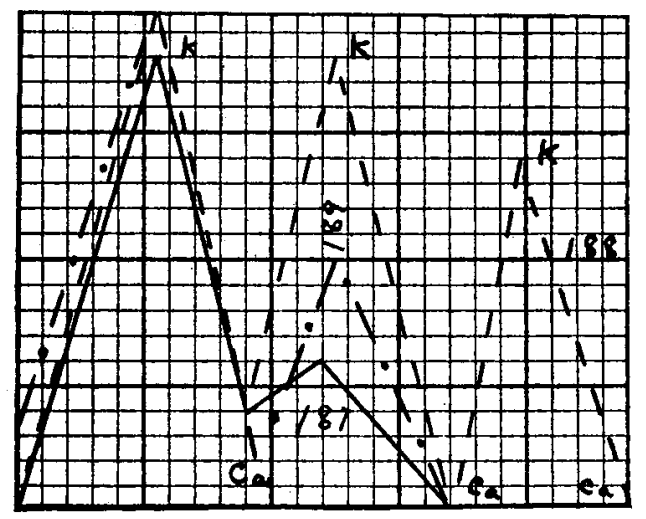

Fig. 3 Showing antagonistic action of $\mathrm{N} / 10$ potassium chloride and $\mathrm{m} / 5 \mathrm{cal}-$ cium chloride on positive rheotaxis of three isopods. For explanation see text.

After about two minutes they were placed on filter paper and introduced into the other solution. Experiments showed that this handling had a stimulating effect but this was not sufficient to mask either the antagonistic effects here recorded or the depressing effects of most salts tried.

The method of charting is the same in all three figures. One space in the ordinates is worth 5 per cent, one in the abscissae equals five minutes. The lines show the variation in the percentage of positive responses given and in all cases at the beginning of the treatment, the low points mark the response when treated with calcium, the high ones when treated with potassium chloride. The only exceptions are found in figure 
5 after the isopods had been treated with alternating solutions for over two hours. The reactions of the different individuals are shown by the different lines and are duly labeled in the figures. No. 188 is repeated in figure 4 for the sake of comparison. Figures 3 and 4 are from work done in 1913 with N/10 potassium against $\mathrm{M} / 5$ calcium chloride and figure 5 is from 1914 results with both solutions $1 / 10$ normal.

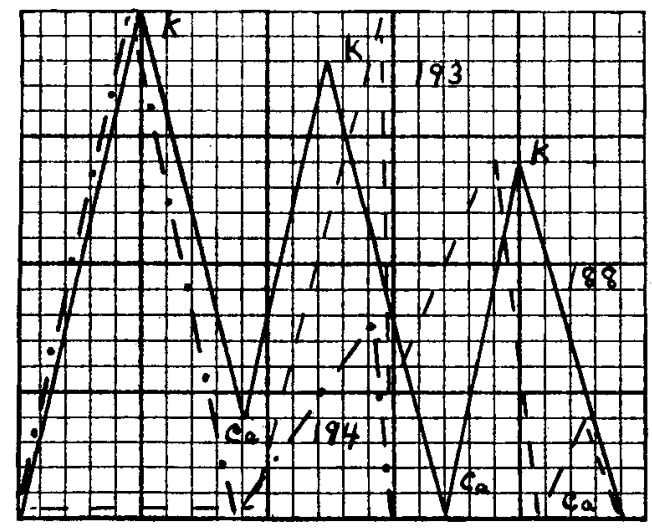

Fig. 4 Showing antagonistic action of $\mathrm{N} / 10$ potassium chloride and $\mathrm{m} / 5$ calcium chloride on positive rheotaxis of three isopods. For explanation see text p. 175 .

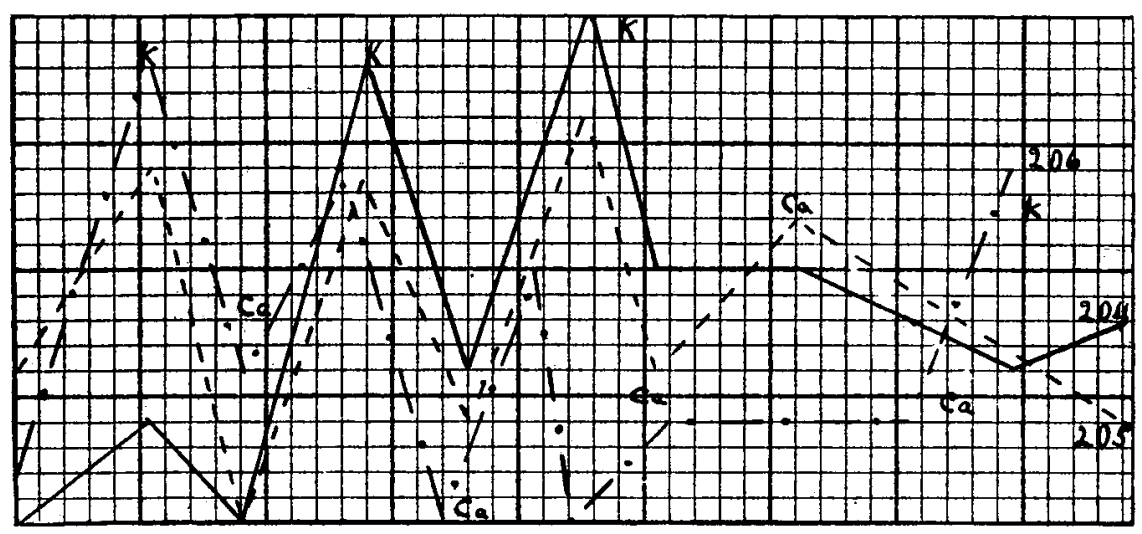

Fig. 5 Showing antagonistic action of $\mathrm{N} / 10$ solutions of potassium and calcium chlorides on positive rheotaxis of three isopods. For explanation see p. 175 . 
Tests were made for similar antagonisms between sodium and magnesium chlorides which are less effective in influencing the rheotactic response than the ones just given. No evidence of marked antagonism was found until the isopods were left in the different solutions for several hours when a definite antagonism was exhibited as is recorded in figure 6 where each space in the abscissae represents an hour.

\section{Acids ( $H$ ions)}

It is particularly hard to summarize in brief form detailed results of the experiments with acids. Preliminary tests were run with acetic, $\mathrm{N} / 100$, hydrochloric; N/50, N/100, N/500

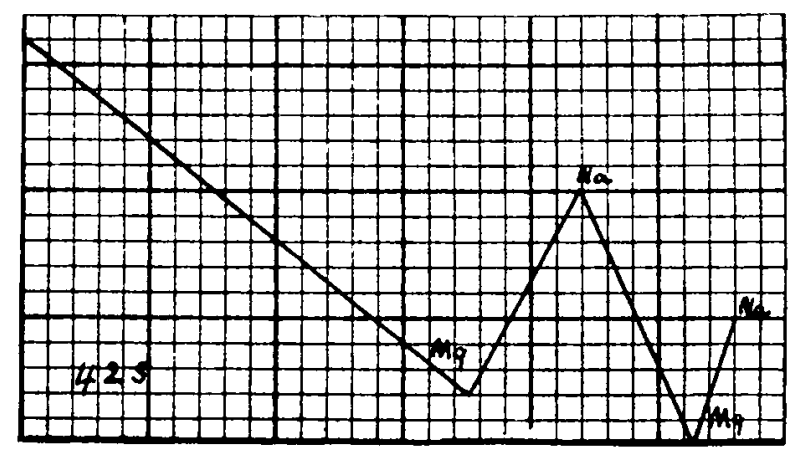

Fig. 6 Showing antagonistic action of $\mathrm{N} / 5$ sodium and magnesium chlorides on positive rheotaxis of one isopod.

and $\mathrm{N} / 1000$; sulphuric, $\mathrm{N} / 100, \mathrm{~N} / 500$, and $\mathrm{N} / 1000$; and with nitric acid $N / 100$. There was some slight evidence of stimulation with $\mathrm{N} / 1000$ hydrochloric and with $\mathrm{N} / 100$ acetic acids. These reagents accordingly were tried again the following season and 3 isopods with $\mathrm{N} / 100$ acetic acid showed complete depression while 15 trials with 6 isopods using $N / 1000$ solution of the same acid showed depression in all cases save one. A similar repetition with $\mathrm{N} / 1000$ hydrochloric showed only one stimulation.

To test the matter further a fairly complete series was run with $\mathrm{N} / 4000$ hydrochloric acid the results of which are shown in figure 7 . In this series 36 trials were made with 14 isopods 


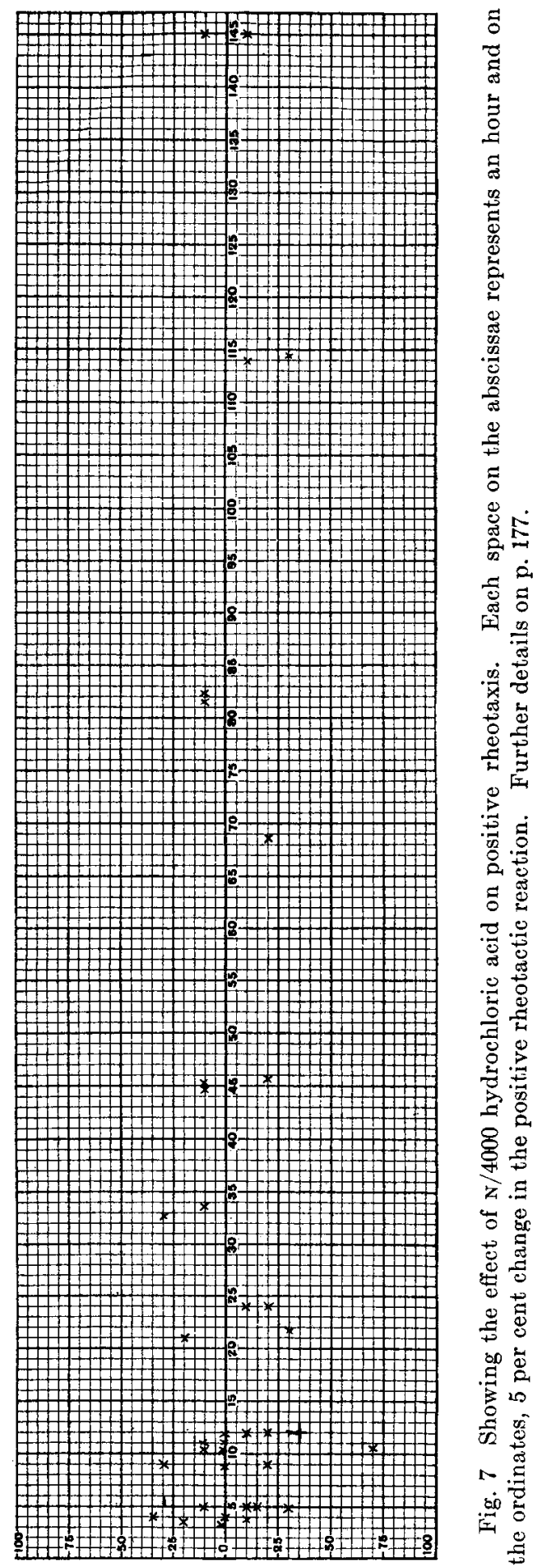


whose initial response was under 71 per cent positive with one exception where the reaction was 90 per cent positive at the start. This individual was made more positive by the action of the acid and so may fairly be included (p. 178). Each space in the abscissae represents one hour and in the ordinates 5 per cent change in the positive rheotaxis. The location of the cross gives then the increase or decrease in the positive rheotaxis and the time that the isopod had been subjected to the treatment. The crosses on the base line indicate in this experiment that neither before nor after the treatment did the isopods give a positive response.

In brief the results show that 14 tests of 5 isopods showed an increased positiveness averaging 15 per cent, 6 tests showed no change in the positive reaction though considering the change in negative, indefinite and zero responses each indicated a depression; and that in 16 tests 9 isopods showed a decrease averaging 21 per cent. As a final summary 39 per cent of the trials showed some increase but the average amount of change in the positive reaction was a decrease of 13 per cent. This is similar to the results obtained with magnesium chloride and indicates a depression.

In the more concentrated solutions acids are decidedly toxic as is shown by the following records for hydrochloric acid:

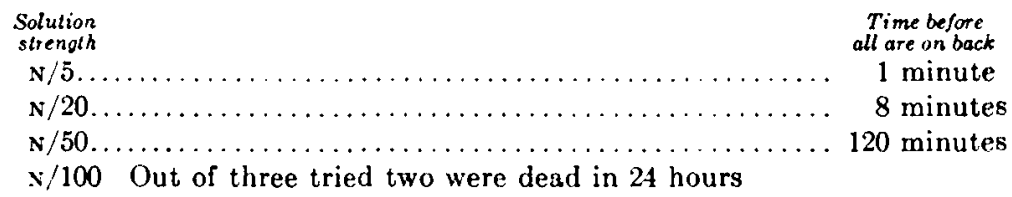

The toxicity was greater than with any other chlorine compound tried and by the usual reasoning in such cases this must be ascribed to the hydrogen ion and the depressing action of acids on rheotaxis must also be ascribed to this ion because each anion tried had the opposite effect on rheotaxis when combined with some other cation. By this I do not mean to maintain that the action of the cation is necessarily direct but that the cation here is the important part of the combination either through its direct action or because it fails to entirely 
neutralize the effect of the anion. As to which of these possibilities is correct my work offers no direct proof.

The depressing effect of acids on nervous tissue is well known to physiologists (Mathews '04). They antagonize sodium chloride (Osterhaut '14) but less than calcium chloride and they depress permeability as also does calcium. The effect on rheotaxis is in accord with this work but with it opposes the observations of Bohn ('12) that N/1000 sulphuric acid increases the oxidation rate of lobster larvae and thereby causes them to become positive to light, and those of Lillie ('09) that $N / 400$ and weaker solutions of hydrochloric acid increase permeability and stimulate Arenicola larvae.

\section{Alkalies (OH ions)}

Mathews ('04) found that hydroxyl ions are most efficient nerve stimulants. Bohn ('12) found that lobster larvae were made positive to light by $\mathrm{N} / 1000$ sodium hydroxide and states that the action is similar to that of sulphuric acid but less rapid. Loeb and Wasteneys ('13 a) report that sodium hydroxide has no effect on the rate of oxidations of fertilized Strongylocentrotus eggs unless the concentration is above N/1000 and ('15) that this minimal concentration varies with different species. More concentrated solutions cause a marked increase in the oxygen consumption but the eggs are injured. Osterhaut ('14) found that in the above strength sodium hydroxide makes practically no change in the permeability of Laminaria. Kanda, ('14) using $\mathrm{N} / 20$ potassium and sodium hydroxides obtained no reversals in geotaxis with Arenicola larvae although in common with Bohn and earlier workers he did obtain reversals in the reaction to light. Lillie ('09) using $\mathrm{N} / 25-\mathrm{N} / 100$ sodium hydroxide found no stimulation of Arenicola larvae and suggests that it decreases permeability.

Potassium and sodium hydroxides were tested for their effect on rheotaxis, the former in N/50 and N/200 solutions and the latter in $N / 200$ and $N / 500$. With the weaker solution of potassium hydroxide two of six isopods were slightly stimulated and 
the average rheotactic reaction was depressed by $25-37$ minutes treatment from $40,32,28$ to $23,25,52$ per cent positive, negative and indefinite. The isopods lost correlation in this solution in about two hours making the toxieity-depression ratio approximately 31 per cent which is the lowest ratio shown by any potassium salt. None of the six isopods tested with sodium hydroxide were made more positive and the average rheotactic reaction was also markedly depressed.

These results with alkalies obviously are based on too little work to conclude that hydroxyl ions will not stimulate positive rheotaxis but since there was no evidence of such stimulation the tests were discontinued.

\section{Distilled water}

To what extent are the results just recorded due to osmosis? It will be remembered that $A$ sellus is a fresh water isopod inhabiting in this case pond water that must exert some osmotic pressure, especially during the summer season when the solutes present are more concentrated. Obviously however the effects recorded cannot all be due to osmosis because as has been shown equimolecular solutions of certain of the salts had opposite effects. For example N/10 potassium chloride with an osmotic pressure of about four atmospheres is very efficient in causing isopods to give a more positive response. The same strength solution of calcium chloride with an osmotic pressure only slightly greater has the opposite effect. In all probability these were more concentrated than the pond water to which the isopod-were accustomed.

By the use of distilled water it is possible to obtain a condition where the osmotic pressure is less than that of the pond water though the action of distilled water may be due to some other factor than osmosis. Water redistilled in glass is quite toxic for these isopods but the water furnished by automatic laboratory stills will allow the isopods to live as long as five days. Bullot ('04) obtained similar results with the fresh water Gammarus. 


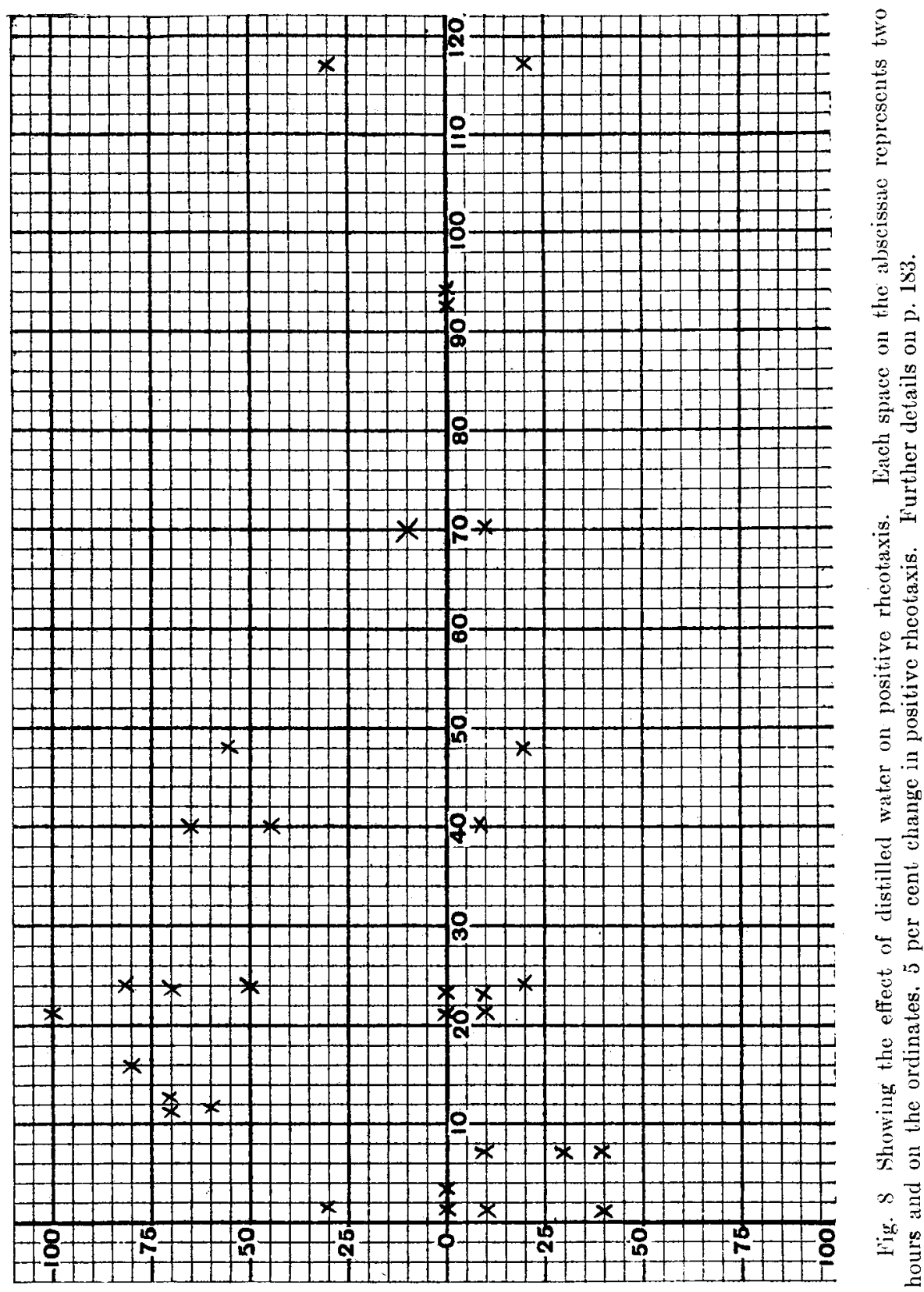


The results of experiments with 11 isopods are shown in figure 8. The charting is the same as in the preceding figure except that the abscissae spaces represent two hours in place of one. As usual, responses obtained from isopods with an initial reaction of over 70 per cent positive are disregarded. Of the isopods tested 55 per cent were stimulated at some time during their treatment. The 17 of the 35 tests which showed some increase in the positive response averaged 49 per cent more positive than before treatment. Six showed no change in the positive reaction and the 12 trials that were less positive gave an average decrease of 24 per cent. Altogether there was an average increase in positiveness of 16 per cent for the 35 trials.

Peters ('04) found that 'very pure' distilled water causes Stentor to lose salts but that the animals do not swell, i.e., there is no intake of water. Garrey (vide Mathews '04) reports that treating Chilomonas with distilled water increased their irritability and Mathews suggests this is because the protoplasm is brought more nearly to the neutrality point. However it is possible that there is an intake of water and there is some evidence (Riddle '14) that such an increase would result in an increased metabolic rate which could account for the increase in positive rheotaxis. This subject will be considered further on p. 186.

\section{NON-ELECTROLYTES}

\section{Cane sugar}

Cane sugar (rock crystal sugar) in $\mathrm{M} / 2$ solution exerts an osmotic pressure of about 12 atmospheres (see references to work of Morse and his students in literature list) ${ }^{3}$ which is near three times that exerted by N/10 potassium or calcium chlorides and if the depression or stimulation results given by these salts were due to osmosis cane sugar should give greatly increased effects. That the sugar at this strength causes depression is shown in table 4 , which exhibits results obtained by exposing 24 isopods to $M / 2$ cane sugar for 52-75 minutes. As usual

${ }^{3}$ Garrey ' 15 found that $1 / 2$ G. M. cane sugar solution gave -1.15 to -1.155 which would give an osmotic pressure of about 14 atmospheres. 
the reactions of isopods with a high initial positive response are not considered.

The averages show that from a rheotactic reaction of 13,73 , 12,2 per cent respectively positive, negative, indefinite and zero the isopods were changed to $11,19,63,7$. The decrease in positiveness is insignificant but the decreuse in the negative reaction and the accompanying increase in indefinite responses shows depression in animals with a low initial positive reaction

\section{TABLE 4}

Showing the effect of $\mathbf{M} / 2$ cane sugar solution on rheotaxis of isopods with an initial response of less than 71 per cent positive. In all cases reported the treatment was from 52 to 75 minutes.

$I$ indicates an increase and $D$ a decrease in positive rheotaxis caused by the treatment

\begin{tabular}{|c|c|c|c|c|c|c|c|c|c|c|c|c|}
\hline \multicolumn{7}{|c|}{ BEFORE TREATMENT } & \multicolumn{6}{|c|}{ AFTER TREATMENT } \\
\hline No. & + & - & $\alpha$ & 0 & E. & Size & + & - & $\alpha$ & o & E. & Effeet \\
\hline 237 & & 20 & 80 & & 1.1 & 6.5 & & 50 & 40 & 10 & 1.0 & I \\
\hline 239 & 70 & 10 & 20 & & 1.8 & 7.0 & & & 80 & 20 & 0.7 & D \\
\hline 244 & & 90 & 10 & & 1.7 & 6.0 & 20 & & 80 & & 1.4 & $I$ \\
\hline 245 & 10 & 80 & 10 & & 1.7 & 6.5 & & 40 & 50 & 10 & 1.2 & D \\
\hline 246 & & 50 & 20 & 30 & 0.9 & 7.0 & & 10 & 90 & & 0.6 & D \\
\hline 247 & 70 & 10 & 20 & & 1.4 & 6.0 & 30 & 20 & 60 & & 0.9 & D \\
\hline 248 & 40 & 30 & 20 & 10 & 1.5 & 7.0 & 20 & 30 & 50 & & 0.9 & D \\
\hline 249 & & 90 & 10 & & 2.4 & 8.0 & & 10 & 80 & 10 & 0.7 & D \\
\hline 260 & & 100 & & & 2.2 & 7.0 & & 20 & 80 & & 1.0 & D \\
\hline 261 & & 100 & & & 2.0 & 6.5 & & 30 & 10 & 60 & 1.2 & I \\
\hline 263 & 30 & 70 & & & 0.7 & 8.0 & & & 40 & 60 & 0.7 & D \\
\hline 265 & & 100 & & & 2.3 & 6.0 & 30 & 30 & 40 & & 1.6 & I \\
\hline 266 & & 90 & 10 & & 2.1 & 7.0 & & & 60 & 40 & 0.4 & D \\
\hline 267 & 10 & 90 & & & 2.3 & 7.5 & & & 70 & 30 & 0.7 & $\mathbf{D}$ \\
\hline 283 & 10 & 90 & & & 2.1 & 5.0 & & & 100 & & 0.7 & D \\
\hline 285 & & 100 & & & 2.3 & 7.0 & & & 100 & & 0.6 & D \\
\hline 280 & & 100 & & & 1.2 & 5.0 & & & 60 & 40 & 0.4 & D \\
\hline 281 & & 100 & & & 1.8 & 6.5 & 20 & 10 & 60 & 10 & 1.3 & I \\
\hline 282 & & 10 & 90 & & 2.0 & 7.5 & 30 & 40 & 30 & & 1.6 & I \\
\hline 277 & 50 & 50 & & & 2.0 & 7.0 & & & 70 & 30 & 1.1 & D \\
\hline 278 & & 100 & & & 2.5 & 8.0 & 50 & 10 & 40 & & 1.2 & I \\
\hline 286 & 10 & 90 & & & 1.6 & 6.0 & & & 100 & & 0.6 & D \\
\hline 287 & & 100 & & & 1.6 & 6.0 & 10 & 50 & 40 & & 1.0 & D \\
\hline 288 & 10 & 80 & 10 & & 1.9 & 7.0 & 20 & 10 & 70 & & 0.8 & $I$ \\
\hline Ave... & 13 & 73 & 12 & 2 & 1.8 & 6.5 & 11 & 19 & 63 & 7 & 0.9 & \\
\hline
\end{tabular}


just as a decrease in positiveness does when isopods are highly positive at the start. Nine isopods or 38 per cent of those tested were stimulated by this treatment for this length of time. The isopods reacted to water currents after fourteen hours exposure to sugar solutions and fully recovered from the depression when placed in tap water. Needless to say the longer treatment caused a greater depression.

Although cane sugar depresses positive rheotaxis it does not do so to the extent that would be expected if the effects of the calcium ions reported above were due to osmosis. No experiments were run testing whether or not the effects of sugar could be offset by different ions as in muscle or nerve preparations but three attempts at recovery using distilled water were somewhat successful. The best case follows: The rheotactic reaction of isopod 290 was changed by three hours treatment with $M / 2$ cane sugar from 80 per cent positive, 20 per cent indefinite to 20 per cent negative, 60 per cent indefinite, 20 per cent zero. After 3 hours 30 minutes in once distilled water the response was 60 per cent positive, 40 per cent indefinite. This is not the expected result if distilled water acts by a differential removal of salts for cane sugar should act in the same manner. Loeb ('03) found with a marine Gammarus that distilled water and cane sugar solutions had approximately the same toxic effect and ascribed this to the loss of electrolytes or ions in to each solution. He suggested that the exit of antagonistic salts takes place with unequal rapidity or in unequal relations. If the effect on rheotaxis were explained on this basis one would have to assume that calcium or strontium salts escape into distilled water and potassium or sodium salts into cane sugar and finally that by withdrawing first enough of one set and then enough of the other the rheotactic reaction would be restored to its original condition. This may be what happens but the observed results can be amply and more simply explained on the basis of a change in water content, with the distilled water allowing an increase in water which should increase the metabolic rate as suggested above and the cane sugar removing water which should decrease the rate of metabolism, and this is what actually happens under treatment with cane sugar (p. 193). 


\section{METABOLISM AND RHEOTAXIS}

Child ('15 and citations) has established a relationship between the metabolic rate of many lower animals and plants and their resistance to potassium cyanide. Hyman ('16, 16a) obtained similar results for certain annelids and sponges and I have found that this relationship holds for Asellus (14). Geppert ('89) for certain mammals and birds, Warburg ('10), Loeb and Lewis ('02), Loeb ('06) and Loeb and Wasteneys ('10, '13) for sea urchin eggs found that the addition of cyanide decreased markedly the oxygen consumption; Hyman ('16 a) gives more detailed results of this relationship with sponges. It appears more than probable that the cyanide acts by affecting the oxidations but as Child ('14) says:

Susceptibility to cyanide in concentrations which are lethal within a few hours varies with the general rate of metabolic activity or of certain fundamental metabolic reactions. This conclusion holds whether the cyanide acts more or less directly upon oxidations or upon the condition of the metabolic substratum or certain of its constituents and so indirectly upon metabolism in general.

Does resistance to sodium cyanide measure the metabolic rate of Asellus?

Certain observations that isopods much depressed by treatment with calcium chloride became more active after being put into N/1000 potassium cyanide and that isopods from potassium chloride did not, led to a fear that the cation even in this dilution might have some effect on the death point, particularly with isopods previously treated with either of the above salte. For this reason it was thought desirable to substitute sodium cyanide with its less toxic and less stimulating cation. The expectation was not entirely realized for animals treated with calcium chloride until they had lost power to move regained it slightly in sodium cyanide. It is possible that the cyanide itself causes a slight initial stimulation (Loevenhart '06), Hyman ('16 a).

The use of sodium in place of potassium cyanide required a retesting to determine what strength, if any, would measure 


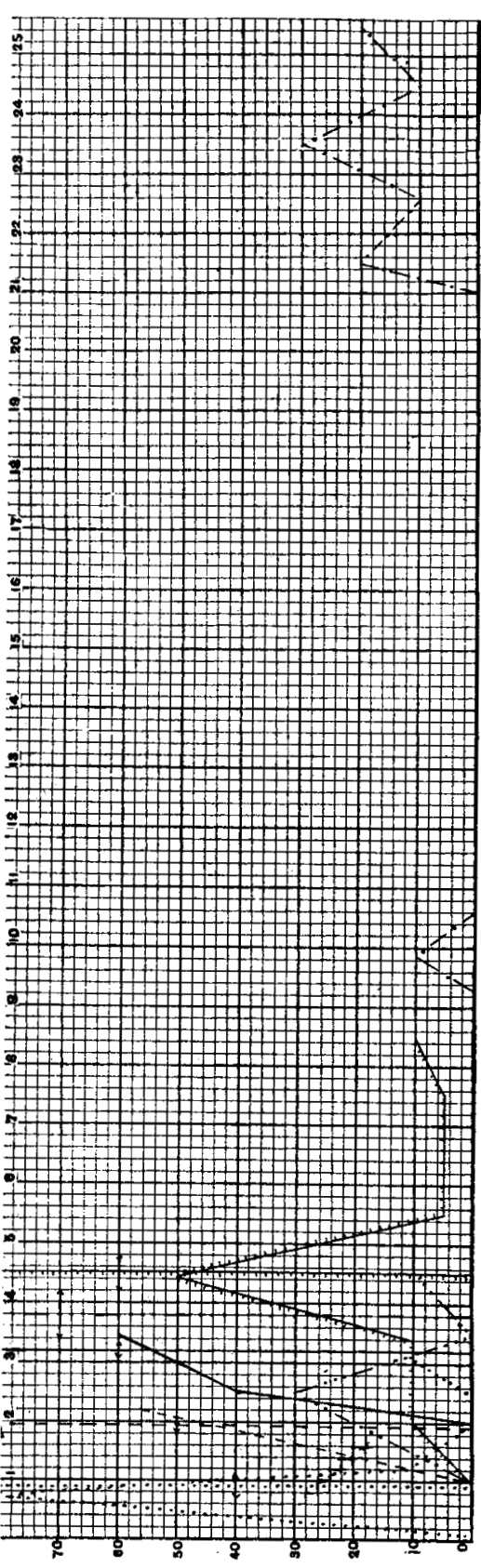

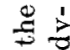

0

क्ष

己

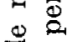

롱

仓

됴 क⿺

丞

范

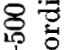

웜

学莺

임

足

表

.

矛我

$\infty \dot{2}$

\&

헌 윰 믈

동

F

녕 훙

8

肎兽富

$\$+\infty$

莡灾

品

范要

n

专 8

Ð. 败

$+20^{\infty}$

焉

so $4=$

严击

息步

or.

os $=$

=1

总. 
the metabolic rate of Asellus. The results of this inquiry are shown in figure 9. In this figure the broken line gives the survival time of 7 small isopods, averaging $4.3 \mathrm{~mm}$. long, in $\mathrm{N} / 400$ concentration. This is to be compared with the unbroken line which gives the resistance of 5 isopods that averaged $7.1 \mathrm{~mm}$. long. The temperature in both cases was $24^{\circ} \mathrm{C}$. The vertical lines give averages and the arrows show the extent of the probable error which here is less than a fourth of the difference.

The dotted line gives the resistance of 10 isopods $5.6 \mathrm{~mm}$. long in N/500 solution whose temperature had been raised 6 to $8^{\circ}$. This is to be compared with the dot-dash line which gives the survival time of the same number of isopods $5.8 \mathrm{~mm}$. long in the same solution strength whose temperature had been lowered $16^{\circ}$.

The dash-three-dot-dash line represents the survival time of 10 isopods which were stimulated by shaking. The average length of these animals was $5.8 \mathrm{~mm}$; the temperature $24^{\circ}$; the solution strength $\mathrm{N} / 500$. Shaking greatly hastens the loss of equilibrium but after the isopods quit moving, the effect is almost nil. This curve is to be compared with the cross barred line which shows the resistance of 20 isopods under conditions identical with the last but which were not stimulated. The probable error of the averages in this connection is about the same as the difference and taken alone would be meaningless but it supports the other curves at least to the extent that the difference is in the same direction.

We have here good evidence that young isopods and those at a higher temperature have a shorter survival time in cyanide than older animals or those at a lower temperature, and indications that stimulation by shaking also increases the susceptibility. If the cyanide is a measure of the metabolic rate of Asellus these results are logical.

\section{Effect of potassium chloride on resistance to sodium cyanide}

Since potassium chloride was the most efficient reagent found for increasing the positiveness of the rheotactic response the effect of this salt on susceptibility to sodium cyanide would 
give the best evidence obtainable as to whether or not a change in the metabolic state accompanied the increase in positiveness. The extent of rheotactic change is shown in part I of table 5. Of the 49 isopods tested only one had its positiveness decreased by the 7-28 minute treatment with $\mathrm{N} / 10$ solution. The average rheotactic response was increased from 10 to 74 per cent positive. Comparison of the survival time with that shown in part II gives the effect of the treatment with potassium chloride upon the susceptibility to $\mathrm{N} / 400$ sodium cyanide. The resistance of 19 highly negative, untreated isopods was 6.1 $( \pm 0.3)$ hours and of the 49 untreated isopods $4.12( \pm 0.2)$ hours. The difference is approximately two hours which is four times the probable error and therefore statistically significant.

These results are also graphically shown in figure 10 in which the solid line gives the resistance of the 49 isopods after being made positive with potassium chloride and the broken line gives that of the 19 untreated animals. The height above the base line gives the number of isopods dying each hour. The vertical lines again show averages and the double pointed arrows give the extent of the probable error.

Effect of calcium chloride upon resistance to cyanide and upon carbon dioxide production

Opposed to potassium chloride, calcium chloride was the most effective depressing salt found. Its effect on the metabolic rate may be judged both by its effect on resistance to cyanide and on carbon dioxide production.

Seventy-one highly positive isopods were treated with calcium chloride long enough to cause a reversal in rheotaxis and then gave a resistance to $\mathrm{N} / 400$ sodium cyanide of 6 hours 34 minutes ( \pm 4 min.) while 27 highly positive, untreated isopods gave an average resistance to the same strength of cyanide of 5 hours 32 minutes $\left( \pm 13^{\circ} \mathrm{min}\right.$.) The difference here is 3.7 times the probable error. It was not thought necessary to carry this series further because of work done with Dr. Tashiro (Allee 
TABLE 5

Showing the effect of $\mathrm{N} / 10 \mathrm{KCl}$ upon rheotaxis and survival time in $\mathrm{N} / 400 \mathrm{NaCN}$

I. Isopods treated with $\mathrm{KCl}$ until highly positive to a water current. Temper-

\begin{tabular}{|c|c|c|c|c|c|c|c|c|c|}
\hline \multicolumn{3}{|c|}{ RHEOTAXIS AT START } & \multicolumn{4}{|c|}{ AFTER TREATMENT } & \multirow{2}{*}{$\mid \begin{array}{c}\text { TIME IN } \\
\text { KCI IN } \\
\text { MIN- } \\
\text { UTES }\end{array}$} & \multirow{2}{*}{$\begin{array}{c}\text { SIZE IN } \\
\text { MMM. }\end{array}$} & \multirow{2}{*}{$\begin{array}{l}\text { SURVIVAL } \\
\text { TIME IN } \\
\text { NaCN. }\end{array}$} \\
\hline+ & - & $\alpha$ & + & - & $\alpha$ & 0 & & & \\
\hline 5 & 95 & & 65 & 35 & & & 15.0 & 7.0 & $1: 20$ \\
\hline 5 & 95 & & 65 & 35 & & & 15.0 & 7.0 & $2: 15$ \\
\hline 5 & 95 & & 65 & 35 & & & 15.0 & 7.0 & $3: 15$ \\
\hline 5 & 95 & & 65 & 35 & & & 15.0 & 7.0 & $3: 15$ \\
\hline 40 & 60 & & 60 & 40 & & & 15.0 & 7.0 & $1: 15$ \\
\hline 12 & 82 & 6 & 100 & & & & 15.0 & 8.0 & $2: 14$ \\
\hline 12 & 82 & 6 & 100 & & & & 15.0 & 6.0 & $2: 14$ \\
\hline \multirow[t]{5}{*}{12} & 82 & 6 & 60 & 20 & 20 & & 15.0 & 6.0 & $2: 14$ \\
\hline & 100 & & 100 & & & & 7.0 & 5.0 & $6: 09$ \\
\hline & 100 & & 80 & 20 & & & 7.0 & 5.0 & $2: 44$ \\
\hline & 80 & 20 & 20 & & 80 & & 7.0 & 6.5 & $3: 09$ \\
\hline & 40 & 60 & 60 & 50 & & & 14.0 & 5.0 & $4: 10$ \\
\hline \multirow[t]{4}{*}{40} & 60 & & 100 & & & & 14.0 & 5.0 & $5: 10$ \\
\hline & 100 & & 100 & & & & 14.0 & 5.0 & $7: 40$ \\
\hline & 100 & & 80 & 20 & & & 12.0 & 5.0 & $3: 15$ \\
\hline & 100 & & 100 & & & & 12.0 & 6.0 & $1: 50$ \\
\hline 80 & 20 & & 100 & & & & 11.0 & 5.0 & $1: 25$ \\
\hline \multirow[t]{7}{*}{20} & 80 & & 60 & 20 & 20 & & 11.0 & 6.5 & $2: 55$ \\
\hline & 100 & & 80 & & & 20 & 11.0 & 6.5 & $1: 55$ \\
\hline & 100 & & 80 & & 20 & & 11.0 & 7.0 & $2: 10$ \\
\hline & 100 & & 33 & & 33 & 34 & 9.0 & 5.0 & $2: 07$. \\
\hline & 100 & & 100 & & & & 13.0 & 7.0 & $2: 54$ \\
\hline & 20 & 80 & 33 & & 67 & & 9.0 & 6.0 & 3:07 \\
\hline & 100 & & 100 & & & & 14.0 & 7.0 & $2: 27$ \\
\hline \multirow[t]{5}{*}{40} & 40 & 20 & 20 & 80 & & & 13.0 & 5.5 & $6: 12$ \\
\hline & 40 & 60 & 40 & 60 & & & 13.0 & 5.5 & $3: 42$ \\
\hline & 80 & 20 & 80 & 20 & & & 13.0 & 6.0 & $3: 12$ \\
\hline & 60 & 40 & 100 & & & & 13.0 & 6.0 & $6: 12$ \\
\hline & 20 & 80 & 20 & 20 & 40 & 20 & 13.0 & 6.5 & $1: 32$ \\
\hline \multirow[t]{3}{*}{20} & 80 & & 100 & & & & 8.0 & 5.0 & $3: 50$ \\
\hline & 100 & & 70 & 10 & 20 & & 8.0 & 6.0 & $12: 00$ \\
\hline & 100 & & 60 & & 40 & & 28.0 & 6.0 & $2: 55$ \\
\hline 20 & 80 & & 50 & & 25 & 25 & 18.0 & 5.0 & $2: 54$ \\
\hline 40 & 60 & & 100 & & & & 14.0 & 6.0 & $7: 34$ \\
\hline 80 & 20 & & 100 & & & & 14.0 & 6.0 & $10: 30$ \\
\hline \multirow[t]{4}{*}{20} & 80 & & 60 & 40 & & & 14.0 & 7.0 & $5: 34$ \\
\hline & 100 & & 60 & 20 & 20 & & 12.0 & 7.0 & $4: 52$ \\
\hline & 100 & & 80 & 20 & & & 12.0 & 8.0 & $4: 30$ \\
\hline & 100 & & 100 & & & & 22.0 & 10.0 & $3: 52$ \\
\hline
\end{tabular}


TABLE 5-Continued

\begin{tabular}{|c|c|c|c|c|c|c|c|c|c|c|}
\hline \multicolumn{4}{|c|}{ RHEOTAXIS AT START } & \multicolumn{4}{|c|}{ AFTER TREATMENT } & \multirow{2}{*}{$\mid \begin{array}{l}\text { TIME IN } \\
\text { KCl IN } \\
\text { MIN- } \\
\text { UTES }\end{array}$} & \multirow{2}{*}{$\begin{array}{c}\text { SIZE IN } \\
\text { MM. }\end{array}$} & \multirow{2}{*}{$\begin{array}{c}\text { SERVIVAL } \\
\text { TIME IN } \\
\text { NaCN. }\end{array}$} \\
\hline & + & - & $\alpha$ & + & - & $\alpha$ & o & & & \\
\hline & 40 & $\begin{array}{r}100 \\
100 \\
100 \\
100 \\
40 \\
100 \\
100 \\
100 \\
100 \\
100\end{array}$ & 20 & $\begin{array}{r}100 \\
60 \\
100 \\
80 \\
70 \\
60 \\
100 \\
60 \\
70 \\
100\end{array}$ & $\begin{array}{l}40 \\
10 \\
10 \\
20 \\
40 \\
20\end{array}$ & $\begin{array}{l}10 \\
20 \\
20\end{array}$ & & $\begin{array}{l}12.0 \\
12.0 \\
12.0 \\
17.0 \\
12.0 \\
12.0 \\
22.0 \\
15.0 \\
25.0 \\
28.0\end{array}$ & $\begin{array}{l}6.0 \\
7.0 \\
5.5 \\
6.5 \\
7.5 \\
7.5 \\
5.5\end{array}$ & $\begin{array}{r}3: 52 \\
3: 62 \\
6: 47 \\
3: 30 \\
3: 17 \\
2: 47 \\
3: 47 \\
5: 02 \\
13: 00 \\
5: 30\end{array}$ \\
\hline ve. & 10 & 82 & 8 & 74 & 15 & 9 & 2 & 13.8 & 6.4 & $4: 07 \pm 12$ \\
\hline
\end{tabular}

II. Negative, untreated isopods. Temperature 17 to $23^{\circ} \mathrm{C}$.

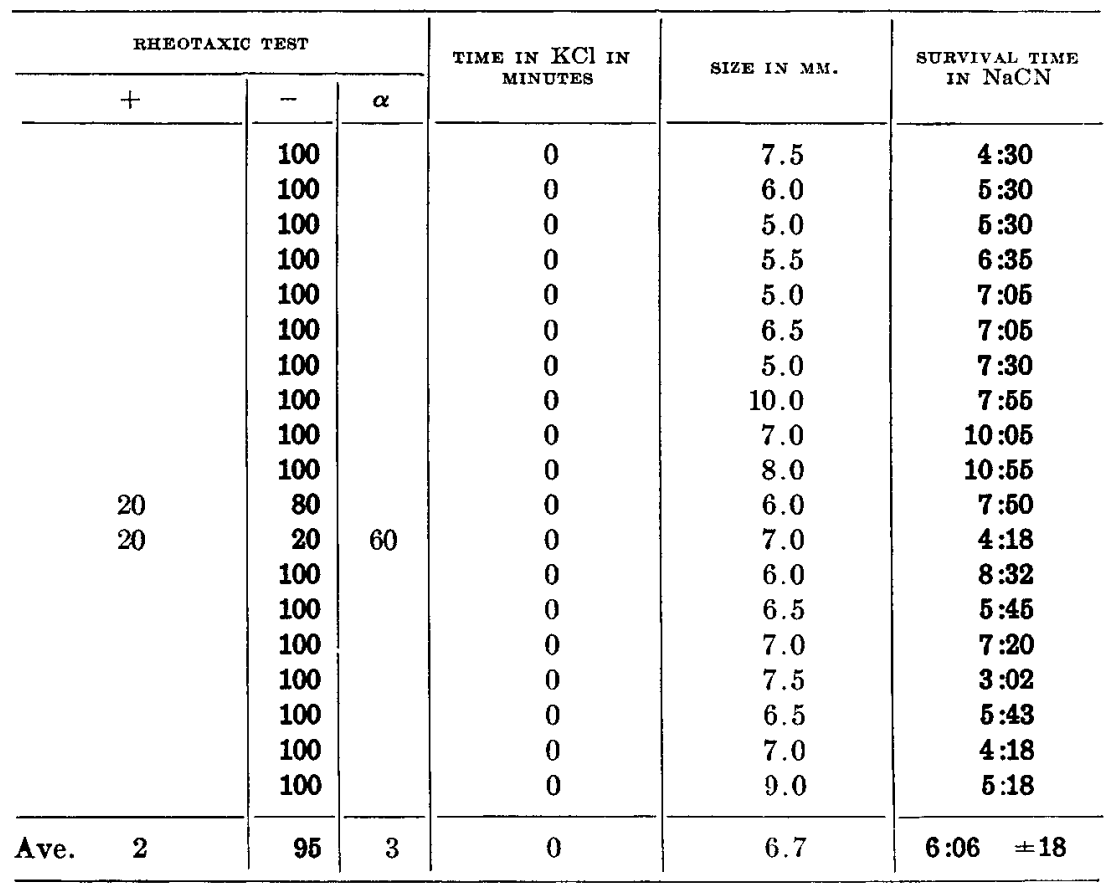




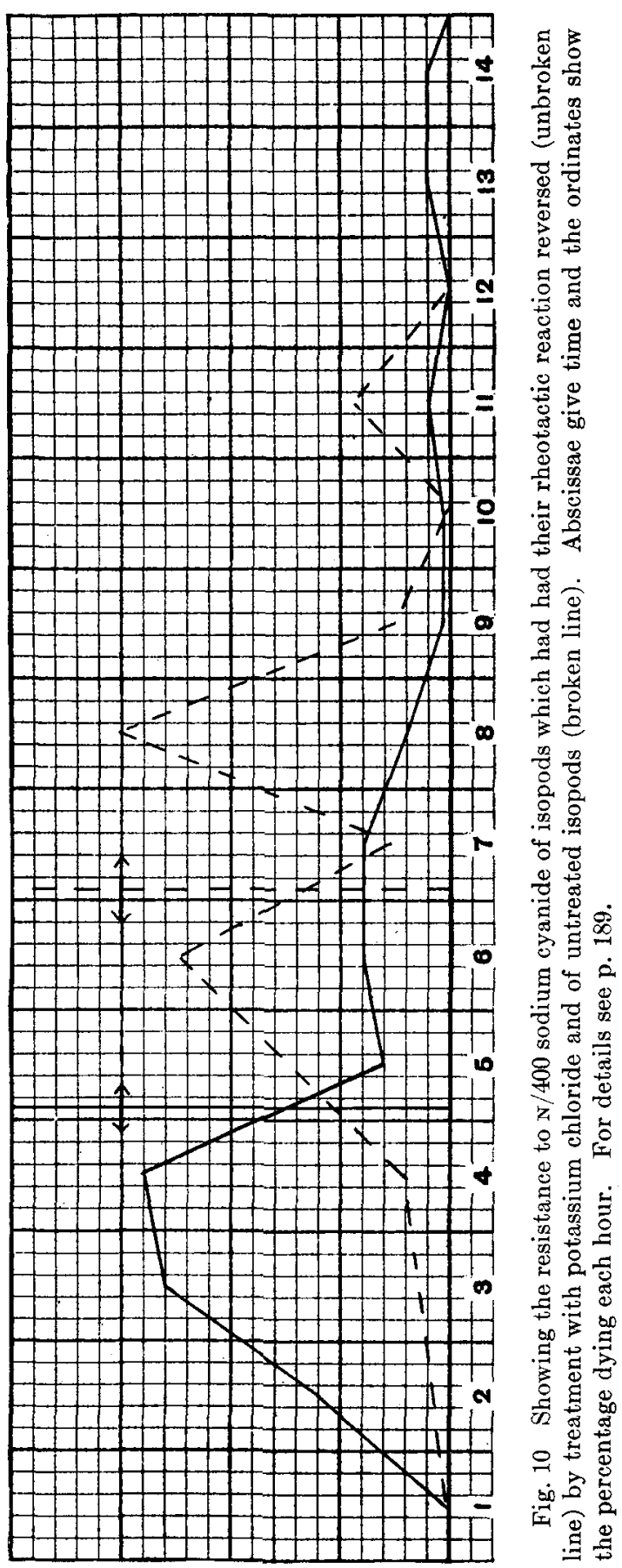


and Tashiro '14) upon the effect of calcium chloride upon carbon dioxide production in Asellus. A part of these results are republished here:

In brief the experiments were as follows: Two isopods of approximately the same size were tested for their relative rate of carbon dioxide production in the Biometer. The isopod having the lower rate of carbon dioxide output was taken as a control and was again tested for the rheotactic reaction and then left in conditions to which it was acclimated while the other was treated. The second individual which had the higher rate of carbon dioxide production was placed in a 0.2 mol. solution of calcium chloride until the tendency to give a positive rheotactic reaction was markedly reduced. Then the rate of carbon dioxide production of the two was again tested in the Biometer.

In both pairs tested the isopod with the higher rate of carbon dioxide production at the first test in the Biometer had also given the higher percentage of rheotactic responses, but after being treated with calcium chloride for 25 to 36 minutes it came to be less positive in its rheotactic reaction, and also gave less carbon dioxide and was less susceptible to potassium cyanide than the control individual. In other words the calcium chloride $(0.2 \mathrm{~mol}$.) decidedly decreased the rate of metabolism of the isopods and also reduced their tendency to give a positive rheotactic reaction.

\section{Effect of cane sugar on resistance to potassium cyanide}

Fifty-four isopods that gave an original average rheotactic response 33, 54, 9, 1 per cent positive, negative, indefinite, and zero were treated with $\mathrm{M} / 2$ cane sugar until they gave an average reaction of $18,24,52,6$. Forty-eight of these were immediately killed in N/1000 potassium cyanide and gave an average survival time of 8 hours 23 minutes ( $\pm 31 \mathrm{~min}$.). Eighty-six isopods that gave an average rheotactic response of $34,57,9$ per cent respectively resisted the same strength of cyanide for an average of 5 hours $( \pm 7 \mathrm{~min}$.). This is a difference of 3 hours 23 minutes which is over five times the probable error and undoubtedly significant. Since the cane sugar probably acted by removing water (Peters '04 for Stentor) we have here excellent evidence that such conditions depress the rate of oxidations in Asellus which corresponds to the results reported by Riddle ('14) for the pigeon's egg. 
TABLE 6

Showing the effect of calcium chloride upon carbon dioxide production and rheotaxis in isopods. The survival time in potassium cyanide is added for comparative purposes. The isopods were first tested for rheotaxis, then two of approximately the same size were taken for determination of their carbon dioxide output in the biometer. The one of these that gave the least carbon dioxide was taken as a control, its rheotactic reaction was again tested and it was allowed to stand in water to which it was accustomed while the other was treated.

The second isopod, the one giving the most carbon dioxide, was placed in a 0.2 mol. solution of calcium chloride until the positive rheotactic tendency was markedly decreased. Immediately afterward the carbon dioxide production of the two was again compared in the biometer.

\begin{tabular}{l|c}
\hline ISOPOD NO. 30 & ISOPOD No. 169 \\
\hline
\end{tabular}

Rheotaxis test, 11:55 A.M. Temp. 20 $50 \%+, 50 \%$ - ; Efficiency, 2.1

Tested in Biometer 1:47-2:00 P.M. Temp. 23.5

Less $\mathrm{CO}_{2}$ than No. 169

Rheotaxis test 2:00 P.M.

$70 \%+, 20 \%-, 10 \%$, Efficiency, 2.25

Tested in Biometer 3:44-3:57 P.M.

More $\mathrm{CO}_{2}$ than No. 169

Survival time in $0.001 \mathrm{Mol}$. $\mathrm{KCN}$ 2 hours, 20 minutes $\sigma^{7}, 4.5 \mathrm{~mm}$. long
Rheotaxis test, 12:25 P.M. Temp. 20 $90 \%+, 10 \%$ - ; Efficiency, 2.1

Tested in Biometer $1: 47-2: 00$ P.M.

Temp. 23.5

More $\mathrm{CO}_{2}$ than No. 30

Put in 0.2 Mol. $\mathrm{CaCl}_{2}$ 2:05 P.M.

Rheotaxis test 2:07 P.M.

$80 \%+, 20 \%-$; Efficiency, 1.6

Rheotaxis test $2: 27$ P.M.

$40 \%+, 20 \%, 40 \%$; Efficiency, .95

Taken from $\mathrm{CaCl}_{2}$ 3:43 P.M. In $\mathrm{CaCl}_{2}$ 36 minutes

Tested in Biometer $3: 44-3: 57$ P.M.

Less $\mathrm{CO}_{2}$ than No. 30

Survival time in $0.001 \mathrm{Mol}$. KCN 3 hours, 10 minutes $\sigma^{7}, 5.0 \mathrm{~mm}$. long

\begin{tabular}{l|c}
\hline ISOPOD No. 171 & ISOPOD No. 84 \\
\hline
\end{tabular}

Rheotaxis test 12:25 P.M. Temp. 20 $10 \%+, 90 \%-$; Efficiency, 2.4

Tested in Biometer 2:49-3:05 P.M.

Little $\mathrm{CO}_{2}$ given off

Less $\mathrm{CO}_{2}$ than No. 84

Rheotaxis tested 3:50 P.M.

$60 \%+, 40 \%-$; Efficiency, 2.0

Tested in Biometer 4:35-5:12 P.M. More $\mathrm{CO}_{2}$ than No. 84

Survival time in $0.001 \mathrm{Mol}$. KCN 1 hour, 35 minutes o', $5.5 \mathrm{~mm}$. long
Rheotaxis test 12:00 M. Temp. 20 $30 \%+, 60 \%-, 10 \%$; Efficiency, 2.6 Tested in Biometer 2:49-3:05 P.M.

Little $\mathrm{CO}_{2}$. given off

More $\mathrm{CO}_{2}$ than No. 171

Put in 0.2 Mol. $\mathrm{CaCl}_{2}$ 4:02 P.м.

Rheotaxis tested 4:07 P.M.

$10 \%+, 40 \%$, 50\%; Efficiency, 0.9

Taken from $\mathrm{CaCl}_{2}$ 4:27 P.M. In $\mathrm{CaCl}_{2}$ 25 minutes

Tested in Biometer 4:35-5:12 P.M.

Less $\mathrm{CO}_{2}$ than No. 171

Survival time in $0.001 \mathrm{Mol}$. $\mathrm{KCN}$ 2 hours, 55 minutes

$\sigma^{7}, 6.0 \mathrm{~mm}$. long 
Since the most efficient stimulating and depressing salts found affect the metabolic rate of the isopods as measured by their resistance to the cyanides and (calcium) by carbon dioxide production the results of these experiments support earlier work on this subject which demonstrated that Asellus with a high rate of positive rheotaxis have a relatively high rate of metabolism and those with a low degree of positiveness tend to have a low rate of metabolism. Lillie ('09) gives evidence to show that the primary action of pure sodium and potassium chloride solutions is to increase, and that of magnesium and calcium chlorides, to decrease permeability in Arenicola larvae and that these stimulate and depress, respectively, the muscular activity of these animals. He concludes that this increase in permeability is in itself sufficient to account for the liberation of energy which is the essential consequence of stimulation. Whether or not the relationship between these salts and rheotaxis can be fully explained on such a basis is a matter for further experimentation.

\section{SUMMARY OF EXPERIMENTAL RESULTS}

The chlorine salts of the alkali metals affect the rheotactic reaction of Asellus communis in such a way as to suggest that there is a relation between the chemical activity of these cations and their effect on rheotaxis of isopods. Potassium is the most effective in increasing the positiveness of the reaction, with rubidium a close second, p. 167.

The relative toxicity of these cations does not run parallel with their stimulating power but resembles the relative favorableness in preserving the activity of frog nerves and muscles p. 170 .

The anions of the most stimulating cation, potassium, affect the rheotactic reaction but their effectiveness does not run parallel with their chemical activity and the relative toxicity, while similar, is not exactly the same as the stimulating power, p. 172.

Any chemical in the concentrations used will cause a decrease in the positive rheotactic reaction, but the chlorine salts of 
calcium and strontium cause this decrease usually without a preliminary stimulation. Magnesium chloride while in the main similar in action often causes preliminary stimulation and barium chloride is still more stimulating, resembling the alkali metals in its effect, p. 173.

In the cations such as potassium which are highly stimulating the depression is a toxic effect while in depressing cations as calcium, rheotaxis is depressed long before toxicity symptoms appear, p. 174.

There is a marked antagonism between the effect of potassium and calcium chlorides and a less marked one between the chlorides: of sodium and magnesium, p. 175.

Both acids ( $\mathrm{H}$ ions) and alkalies (OH ions) in the concentrations used generally decrease the percentage of positive responses given, p. 177 .

Once distilled water gave some evidence of causing Asellus to become more positive in their rheotactic reaction, though pure water was quite toxic, p. 181.

Cane sugar decreased the positive rheotactic reaction probably by extracting water and the action of the once distilled water may be due to water intake, p. 183.

The results obtained with salts are not osmotic effects because equimolecular solutions of different salts with approximately the same osmotic pressure may have opposite effects and because cane sugar in $M / 2$ solution was a less effective depressant than $\mathrm{N} / 10$ calcium chloride although its osmotic pressure is over three times as great, p. 185.

Susceptibility to sodium cyanide $N / 400$ or $N / 500$ measures the rate of metabolism of Asellus probably by limiting the oxygen consumption, p. 188.

Measured in this way, potassium chloride when increasing positive rheotaxis also increases the rate of isopod metabolism, and calcium chloride and cane sugar decrease both positive rheotaxis and the metabolic rate. Calcium chloride also decreases the carbon dioxide output, p. 189. 


\section{LITERATURE CITED}

Allee, W. C. 1912 An experimental analysis of the relation between physiological states and rheotaxis in Isopoda. Jour. Exp. Zoöl., vol. 13, pp. 269-344.

1913 Further studies on physiological states and rheotaxis in Isopoda. Jour. Exp. Zoöl., vol. 15, pp. 257-295.

1914 Certain relations between rheotaxis in isopods and their survival time in potassium cyanide. Jour. Exp. Zoöl., vol. 16, pp. 397-412

Allee, W. C. and Tashiro, Shiro 1914 Some relations between rheotaxis and the rate of carbon dioxide production of isopods. Jour. An. Beh., vol. 4, pp. 202-214.

Bohn, Georges 1912 Les variations de la sensibilité en relation avec les variations de l'etat chimique interne. C. R. Acad. Sc., Paris, T.154, pp. 388-391.

Brodsky, 1908 Dissertation unter Höber, Zurich. Fide Höber, '14, s. 511.

BULzot, G. 1904 On the toxicity of distilled water for the fresh water Gammarus. Suppression of this toxicity by the addition of small quantities of sodium chloride. Univ. of Calif. Publ. in Physiol., vol. 1, pp. 199-217.

Chemiker Kalendar 1913

ChILd, C. M. 1914 Axial gradients in the early development of the starfish. Am. Jour. Physiol., vol. 37, pp. 203-219.

1915 Senesence and rejuvenesence. Chicago, $481 \mathrm{pp}$.

Garrey, W. E. 1915 Some cryoscopic and osmotic data. Biol. Bull., vol. 28, pp. $77-86$.

Geppert, J. 1889 Ueber das Wesen der Blausäurevergiftung. Zeitschr. f. klin. Med. Bd. 15, s. 208-247; 307-369.

HöBer, RUdOLPH 1914 Physikalische Chemie der Zelle und der Gewebe. Leipzig und Berlin, 808 pp.

Hyman, Libbie H. 1916 An analysis of the process of regeneration in certain microdrilous oligochaetes. Jour. Exp. Zoöl., vol. 20, pp. 99-163.

$1916 \mathrm{a}$ The effect of potassium cyanide on oxygen consumption in certain sponges. Am. Jour. Physiol., vol. 40, pp. 238-248.

KANDA, SAKYo 1914 The reversibility of the geotropism of Arenicola larvae by means of salts. Am. Jour. Physiol., vol. 35, pp. 162-173.

LILLIE, R. S. 1909 On the connection between changes of permeability and stimulation and on the significance of changes in permeability to carbon dioxide. Am. Jour. Physiol., vol. 24, pp. 14-44.

1909 a The relation of ions to contractile processes. IV. The influence of various electrolytes in restoring muscular contractility after its loss in solutions of cane sugar and magnesium chloride. Am. Jour. Physiol., vol. 24, pp. 459-492.

LOEB, JACQUES 1903 Relative toxicity of distilled water, sugar solutions, and solutions of the various constituents of sea water for marine animals. Univ. of Calif. Publ. in Physiol., vol. 1, pp. 55-69.

1906 Ueber die Hemmung der Toxischen Wirkung hypertonischer Lösungen auf Seeiglei durch Sauerstoffmangel und Cyankalium. Archiv. f. ges. Physiol., Bd. 113, s. 487-511. 
LOEB, J. AND LEWIS, W. H. 1902 On the prolongation of life in the unfertilized eggs of sea urchins by potassium eyanide. Am. Jour. Physiol., vol. 6, pp. 305-317.

Loeb, J. and Wasteneys, H. 1910 Warum hemmt Natriumcyanid die Giftwirkung einer Chlornatriumlösung fur das Seeigelei. Biochem. Zeitschr. Bd. 28, s. 340.

1913 Is narcosis due to asphyxiation? Jour. Biol. Chem., vol. 14, pp. 517-523.

1913 a The influence of bases upon the rate of oxidations in fertilized eggs. Jour. Biol. Chem., vol. 14, pp. 459-464.

1915 Further experiments on the relative effect of weak and strong bases on the rate of oxidations in the egg of the sea urchin. Jour. Biol. Chem., vol. 21, pp. 153-158.

Loevenhart, A. S. 1906 Ueber die Beschleunigung gewisser Oxydationsreactionen durch Blausäure. Ber. deutsch. chem. Gesellsch., Bd. 39, s. $130-133$.

Mathews, A. P. 1904 Nature of chemical and electrical stimulation. Am. Jour. Physiol., vol. 11, pp. 455-496.

1907 The cause of the pharmocological action of ammonium salts. Am. Jour. Physiol., vol. 18, pp. 58-63.

Meyerhoff, 1911 Die Atmung der Seeigeleier (Strongylocentrotus lividus) in reinen Chlornatriumlösungen. Biochem. Zeit., Bd. 33, s. 291-302.

Morse, H. N., Frazer, J. C. W. And Holland, W. W. 1907 The osmotic pressure of cane sugar solutions in the vicinity of the freezing point of water. Am. Chem. Jour., vol. 37, pp. 424-467.

Morse, H. N. And Mears, B. 1908 The osmotic pressure of cane sugar at $15^{\circ}$. Am. Chem. Jour., vol. 40, pp. 194-213.

Morse, H. N. and Holland, W. W. 1909 The osmotic pressure of cane sugar at $20^{\circ}$. Am. Chem. Jour., vol. 41, pp. 257-276.

Osterhatt, W. J. V. 1914 Effect of alkali on permeability. Jour. Biol. Chem., vol. 19 , pp. $335-345$.

1914 a Antagonism between acids and salts. Jour. Biol. Chem., vol . 19, pp. 517-520.

Peters, A. W. 1904 Metabolism and division in Protozoa. Proc. Am. Acad. Arts and Sci., vol. 39, pp. 441-514.

Riddle, Oscar 1914 The determination of sex and its experimental control. Bull. Am. Acad. Med., vol. 15, no. 5, 20 pp.

Ringer, SidNeY 1886 Further experiments regarding the influence of small quantities of lime, potassium and other salts on muscular tissue. Jour. Physiol., vol. 7, pp. 291-308.

WARBURG, O. 1910 Ueber die Oxydationen in lebenden Zellen nach Versuchen am Seeiglei. Zeitschr. f. Physiol. Chem., Bd. 66, s. 305. 